\title{
Infrasound Signals and Their Source Location Inferred from Array Deployment in the Lützow-Holm Bay Region, East Antarctica: January-June 2015
}

\author{
Takahiko Murayama ${ }^{*}$, Masaki Kanao ${ }^{2}$, Masa-Yuki Yamamoto ${ }^{3}$, Yoshiaki Ishihara ${ }^{4}$ \\ ${ }^{1}$ Japan Weather Association, Tokyo, Japan \\ ${ }^{2}$ National Institute of Polar Research, Research Organization of Information and Systems, Tokyo, Japan \\ ${ }^{3}$ Kochi University of Technology, Kochi, Japan \\ ${ }^{4}$ Japan Aerospace Exploration Agency, Tokyo, Japan \\ Email: ^murayama@jwa.or.jp, kanao@nipr.ac.jp, nakamoto.manami@nipr.ac.jp, yamamoto.masa-yuki@kochi-tech.ac.jp, \\ ishihara.yoshiaki@jaxa.jp
}

How to cite this paper: Murayama, T., Kanao, M., Yamamoto, M.-Y. and Ishihara, Y. (2017) Infrasound Signals and Their Source Location Inferred from Array Deployment in the Lützow-Holm Bay Region, East Antarctica: January-June 2015. International Journal of Geosciences, 8, 181-188. https://doi.org/10.4236/ijg.2017.82007

Received: November 22, 2016

Accepted: February 12, 2017

Published: February 15, 2017

Copyright $\odot 2017$ by authors and Scientific Research Publishing Inc. This work is licensed under the Creative Commons Attribution International License (CC BY 4.0).

http://creativecommons.org/licenses/by/4.0/

\begin{abstract}
Characteristic features of infrasound waves observed in the Antarctic represent a physical interaction relating surface environment in the continental margin and surrounding Southern Ocean. Source location of several infrasound events is demonstrated by using combination of two array deployments along a coast of the Lützow-Holm Bay (LHB), East Antarctica, for data retrieving period in January-June 2015. These infrasound arrays being established in January 2013 clearly detected temporal variations in frequency content and propagation direction of the identified seven large events. Many of these sources are assumed to have cryoseismic origins; the ice-quakes associated with calving of glaciers, discharge of sea-ice, collision between sea-ice and icebergs around the LHB. Detail and continuous measurements of infrasound waves in the Antarctic are a proxy for monitoring regional environment as well as climate change in high southern latitude.
\end{abstract}

\section{Keywords}

Infrasound, Array Observations, Lützow-Holm Bay, East Antarctica, Microbaroms, Ice Shocks, Surface Environment

\section{Introduction}

"Infrasound waves" are defined as subaudible sounds-pressure waves with frequencies ranging from the cut-off frequency of sound $\left(3.21 \mathrm{mHz}\right.$, for a $15^{\circ} \mathrm{C}$ 
isothermal atmosphere) to the lowest frequency of the human audible band (20 $\mathrm{Hz}$ ). Infrasound waves involving large energy sources can propagate for several thousand kilometers or more along the Earth's surface [1]. As an example, the Sumatra-Andaman great earthquake of 26 December 2004 produced not only tsunami waves but also significant infrasound waves in the atmosphere [2] [3]. Thus, the infrasound can be effectively used for remote sensing of physical aspects of the Earth's atmosphere, compared with seismic waves in the same frequency range recorded by a seismometer.

There are several reports of production of infrasound waves by environmental sources such as volcanic eruptions, ocean waves, earthquakes, and the passage of aircraft [4] [5]. In addition, there have been reports of infrasound waves possibly generated by thunder, sprites, fireballs, meteorite falls, the reentry of artificial vehicles, as well as aurora activities in polar region [6] [7] [8]. In polar region, time-space variations in atmospheric pressure are excited by physical interaction between the atmosphere, oceans, cryosphere, and the surface of solid earth. These interactive phenomena are involved in surface environmental variations and their generating sources can be measured by using infrasonic waves in polar region.

In April 2008, infrasound observations started at the Japanese station; Syowa (SYO; $69.0^{\circ} \mathrm{S}, 39.6^{\circ} \mathrm{E}$ ), in the Lützow-Holm Bay (LHB) of Antarctica. The single infrasound sensor at SYO has been continuously recording the data until the present (as of 2016), and has clearly recorded background contamination from oceanic signals (microbaroms) and their long-term variability of frequency contents and power spectrograms [9] [10].

In austral summer 2013 and 2014, several field stations were established along the eastern coast of the LHB. In particular, two infrasound arrays with different diameters were deployed on the outcrop site at SYO together with the second array on continental ice sheet near the eastern coast of LHB. Observation system of the arrays and initial data recorded in austral summer 2013 are already reported [11]. At the initial observation period, moreover, airburst shock waves emanating from a meteoroid entering the atmosphere over the Russian Republic were identified on 15 February 2013.

In this paper, in addition to the previous study, identification of infrasound sources was tried by using the pair of the arrays deploying at SYO and other sites on continental margin of ice sheet. Source location of several striking infrasound events is determined by combination of two arrays for data period in JanuaryJune 2015. Plausible source mechanism of these events is discussed regarding surface environmental change, in particular cryosphere dynamics surrounding the LHB.

\section{Array Deployments}

A total 9 infrasound stations were established in eastern coast of LHB in January of 2013 and 2014 (Figure 1). Two triangle array alignments with different diameters were set up; the first one at SYO (with a $100 \mathrm{~m}$ spacing triangle) and the 


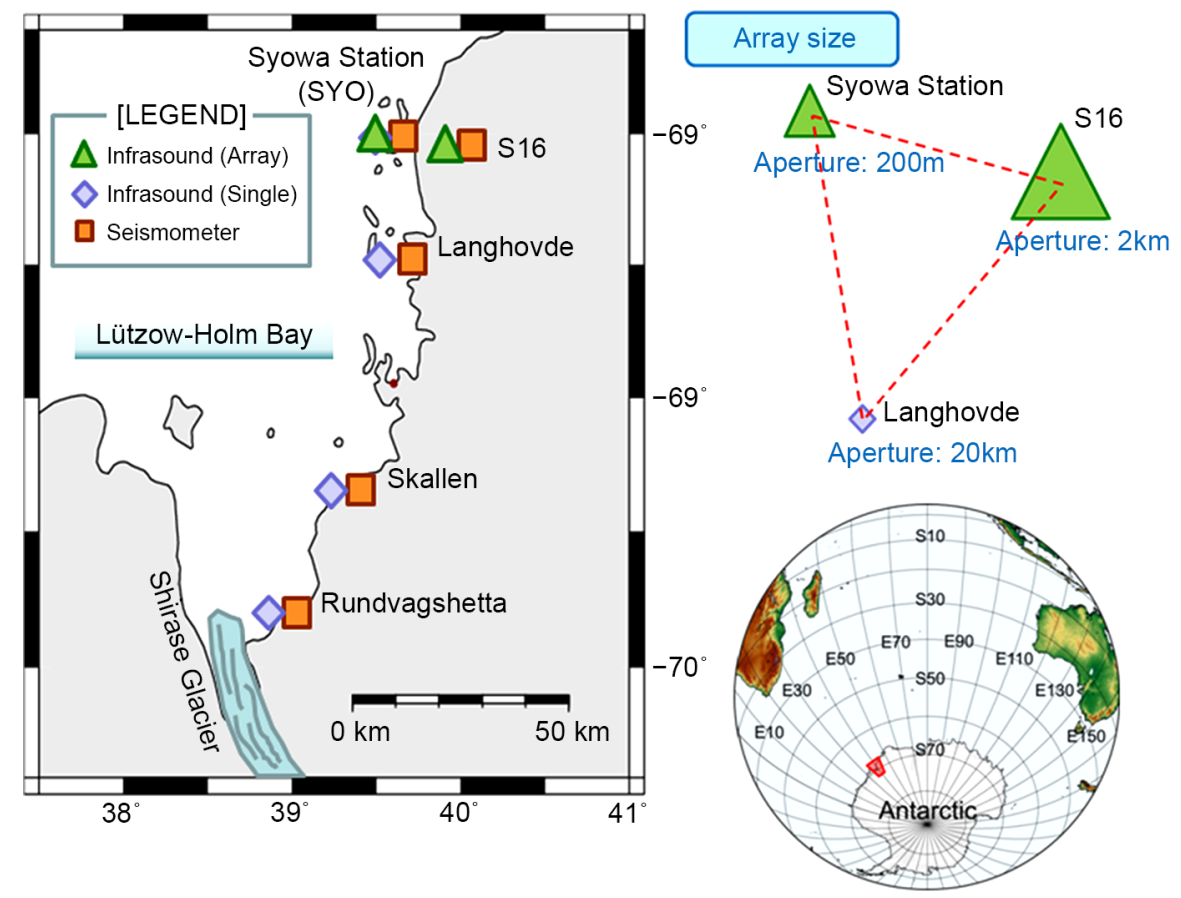

Figure 1. (left) Locations and measurement elements of array deployment around the Lützow-Holm Bay (LHB), East Antarctica. Infrasound array stations (green triangles), infrasound single stations (light blue diamond) and broadband seismometers (orange squares), respectively. (right) Array configuration of infrasound stations to localize the signals. Tripartite arrays are deployed by small size (at Syowa Station (SYO), aperture of $200 \mathrm{~m}$ ), medium size (at S16, aperture of $2 \mathrm{~km}$ ) and large sizes (combined by other outcrop stations such as Langhovde, aperture of $20 \mathrm{~km}$ or larger), respectively.

second one in S16 area on continental ice sheet (with a $1 \mathrm{~km}$ spacing triangle), where is $15 \mathrm{~km}$ eastward from SYO. In addition to these arrays, isolated single stations were deployed at three outcrops (Langhovde Skallen and Rundvagshetta). These multi-scale array configurations of infrasound stations were adopted to localize detected signals efficiently by identifying different wavelengths with corresponding frequencies for each array size (Figure 1).

The Chaparral Physics Model 25 (manufactured by the University of Alaska, USA, with a detectable frequency range of $0.1-200 \mathrm{~Hz}$ ) have been used at majority stations. A schematic illustration of the observation systems is shown in Figure 2. The hose arrays are aligned to reduce wind noise by adopting mechanical low-pass filtering. Multiply-connected porous hoses are utilized at the SYO array, with a single-hose array configuration being adopted at all the other field stations for simplifying the installation. These porous hoses are mainly buried under mounds of stones/snow-ice collected from around the sites to reduce the vibration effect of the wind. More detail configuration of the observation system (power supply, data acquisition and transmission) is given in [11].

\section{Analyses and Discussion}

Several examples of detected infrasound signals and location estimation results from array analyses are presented here. To estimate the propagation directions 


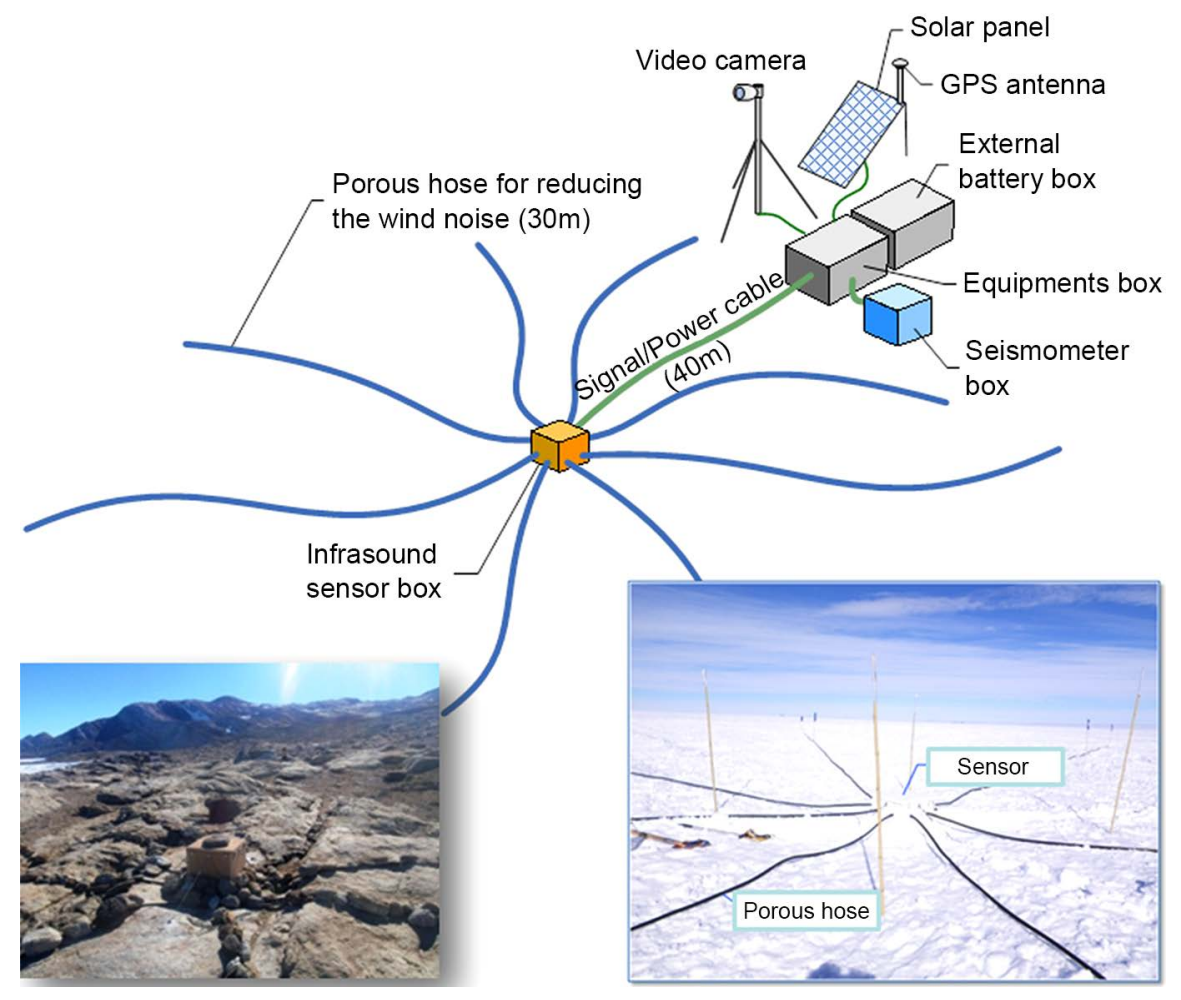

Figure 2. (upper) An external view of observation system at one of the field stations in LHB. The rosette filter configuration for reducing the wind noises composed by eight porous hoses with $30 \mathrm{~m}$ in length, which connect to the infrasound senor box. (lower) Photos of the field station of S16 on the ice sheet (right) and of Langhovde on the outcrop (left).

and event locations of infrasound signals, array analyses were conducted by using both the SYO array (Station ID; C1, C2 and C3) and the S16 array (P50, S16, S17) data (Figure 1). During the period from January to June 2015, seven large events were identified of their source locations and propagation paths to the arrays. Hypocenters were estimated using the progressive multi-channel correlation (PMCC) algorithm [12] [13]. Time-domain infrasound waveforms for identical large events observed by two array stations and the results of array analyses using PMCC are shown in Figures 3-5.

At each figure, the left panels show the band-pass-filtered waveforms observed by the array elements at SYO and the S16. The upper-right panels show the back-azimuth (station-to-source) directions and the apparent velocities of the infrasound signals determined using the PMCC algorithm. The lower-right panels represent the results of event location using the back-azimuth directions on the local map at LHB. Three colored lines correspond the back-azimuth directions from the array stations (SYO and S16), respectively. The center line from each array stations is the most expected orientation. In addition, the ellipsoidal areas (red open circles) at the intersection of three lines indicate the location of source with an uncertainty of $5 \%$.

Figure 3 demonstrated the location of infrasonic signals associated with ice-quakes occurring at the marginal area of continental ice sheet on January 1 , 


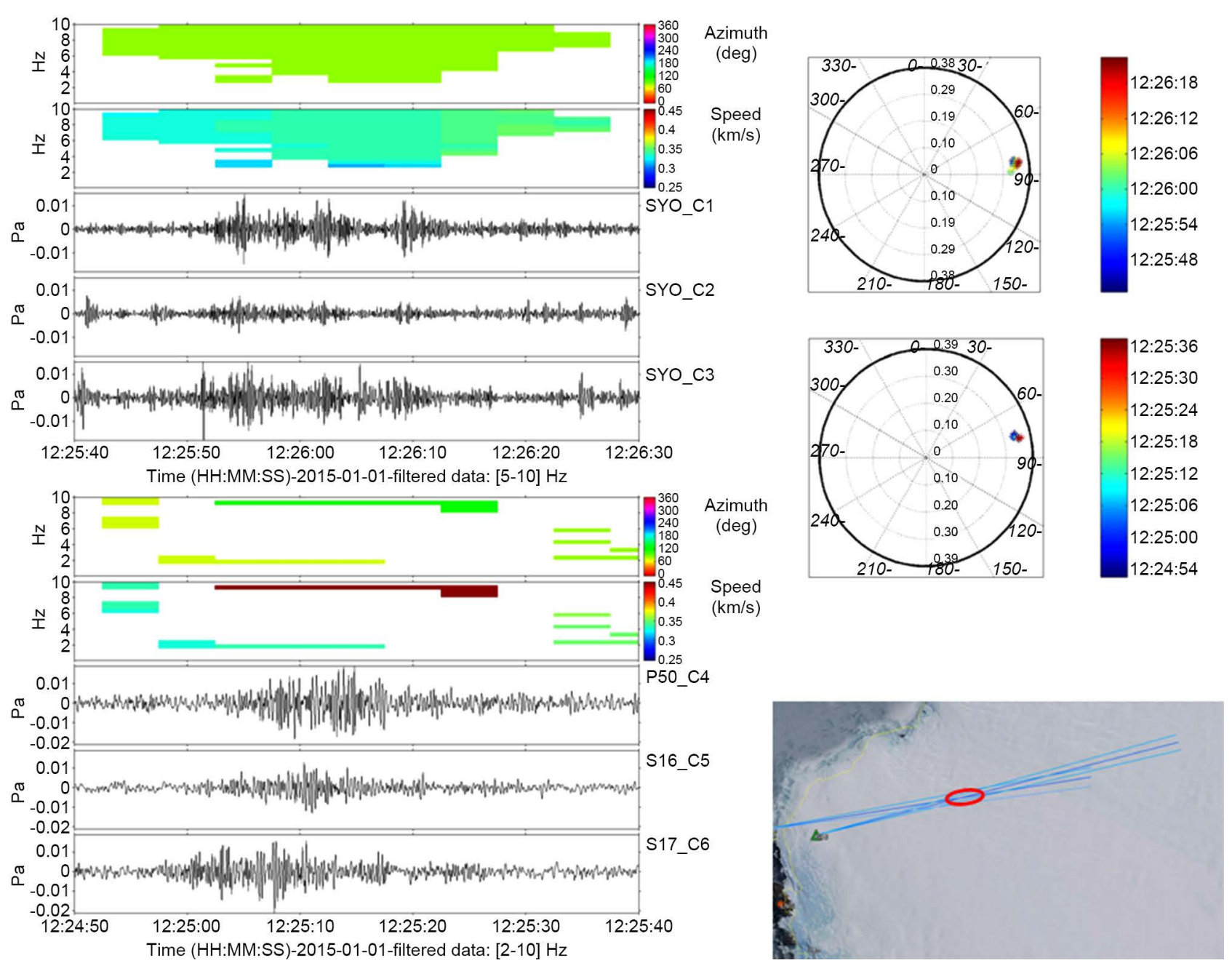

Figure 3. Detection of infrasonic signals associated with the ice-quake on the continental ice sheet on January 1, 2015 (forecasted origin time: 12:22 UTC). The left panels are band-pass-filtered waveforms observed at SYO and S16 arrays, respectively. The upper-right and middle-right panels are the results of PMCC analysis. The diagram shows the back-azimuth (station-to-source) direction and the apparent velocities. The lower-right panel is local area (on Google map) of the estimated event location. Colored lines show the back-azimuth directions from both SYO and S16. Open red circle corresponds to the area of hypocenter of the event.

2015. On the basis of local geographical information, several crevasses exist over the ice-sheet around the area which might generated the infrasound energy following to be detected at both the arrays of SYO and S16. Figure 4 represents the detection of infrasonic signals generated by the calving event at the western margin of ice sheet on June 4, 2015. The events are exactly located at the continental edge between SYO and S16 arrays. The third example of determined location for the infrasound generating source on June 4, 2015 is shown in Figure 5. The detected infrasonic signals were presumably generated by the calving or discharge event at the edge of the fast sea-ice in LHB. The other candidate could be the collision event between the iceberg and the edge of the fast sea-ice.

The other four events were determined to locate around the edge of the fast sea-ice (8 February), inside the LHB presumably associated with sea-ice cracks or pressure ridges (4 June and 29 June), and around the SYO originated by 

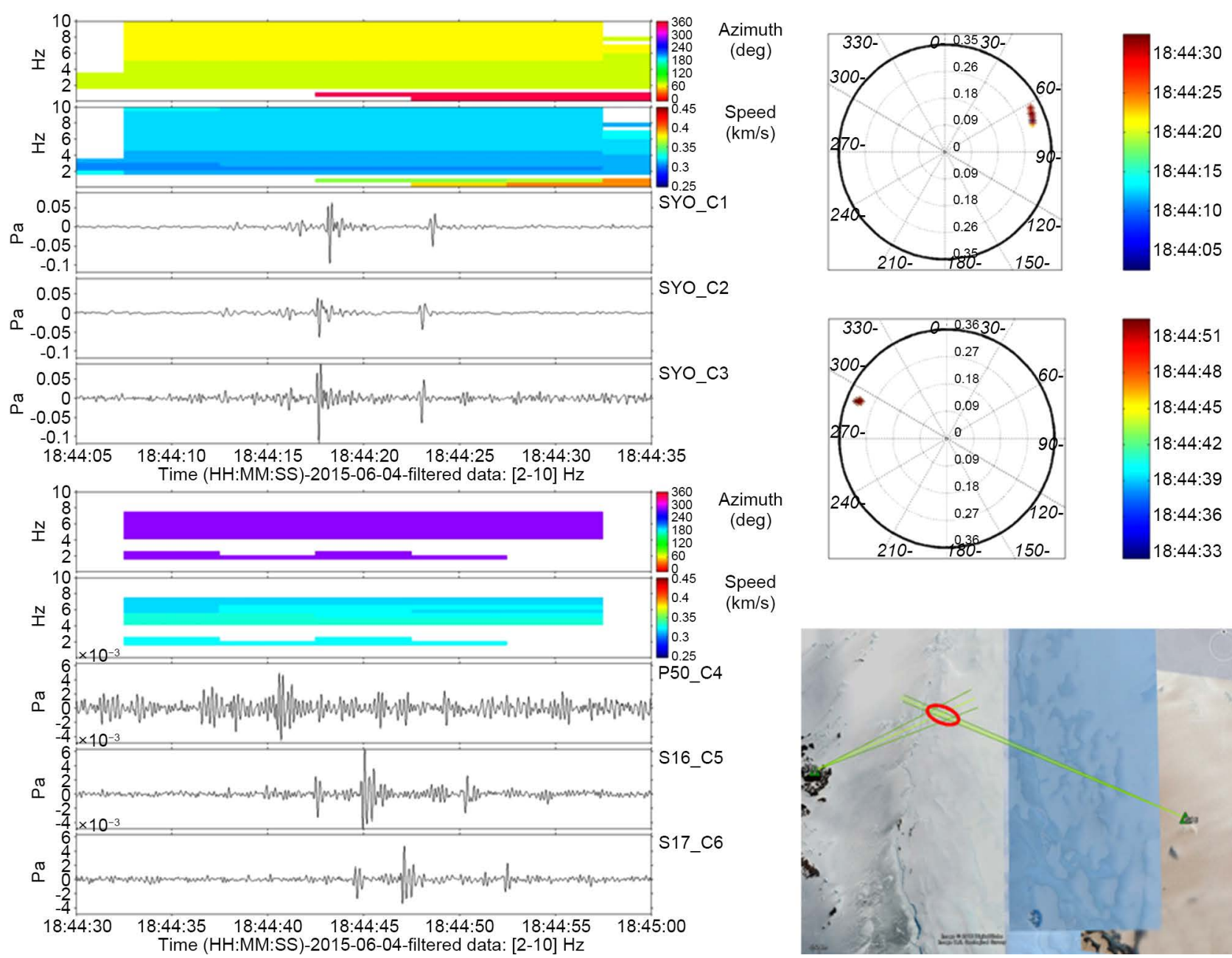

Figure 4. Detection of infrasonic signals generated by the calving event at a margin of continental ice sheet on June 4, 2015 (forecasted origin time: 18:43 UTC). The left panels represent band-pass-filtered waveforms observed at SYO and S16 arrays. The upper-right and middle-right panels are the results of PMCC analysis. The lower-right panel is local area (on Google map) of the estimated event location. Colored lines show the back-azimuth directions from both SYO and S16. Open red circle corresponds to the area of hypocenter of the event.

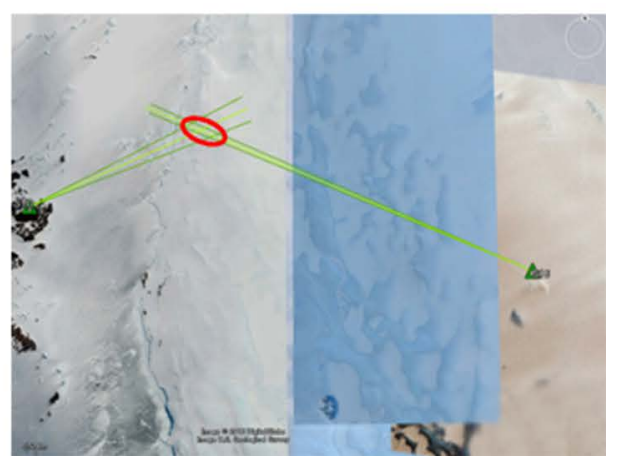

tide-cracks (23 June), respectively. In all the events investigated here, local icequakes, calving of glaciers and/or ice-cliffs, collision of icebergs and sea-ice, as well as the other candidates for generating sources involving cryosphere dynamics might produce distinctive infrasound signals; having high-frequency oscillations ranging between 3 and $8 \mathrm{~Hz}$ and amplitudes between 0.01 and $0.1 \mathrm{~Pa}$. These local signals with high-frequency contents also might be considered to include regional/local earthquakes, however the exact separation for these cryospehre and tectonic origins can be done by future study.

\section{Conclusion}

Characteristic features of infrasound waves are demonstrated in this study by using two array elements at coastal area in LHB of East Antarctica, on the basis of data retrieved in January-June 2015. The infrasound arrays clearly detected temporal variations in frequency content and propagation direction of seven 

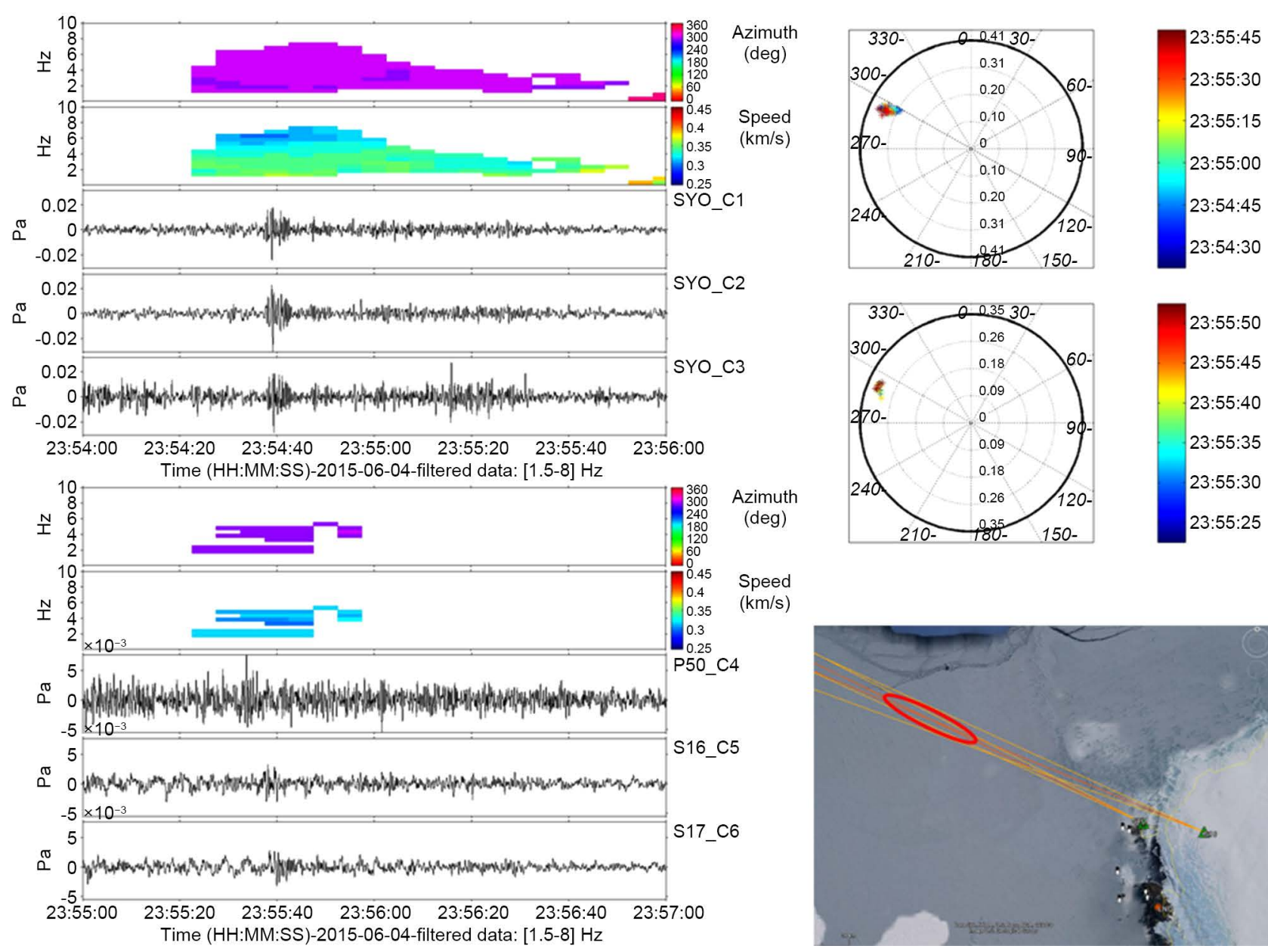

Figure 5. Detection of infrasonic signals presumably generated by the calving/discharge event of the edge of fast-ice in LHB, otherwise the collision event with an iceberg on June 4, 2015 (forecasted origin time: 23:50 UTC). The left panels are band-passfiltered waveforms observed at SYO and S16 arrays. The upper-right and middle-right panels are the results of PMCC analysis. The lower-right panel is local area (on Google map) of the estimated event location. Colored lines show the back-azimuth directions from both SYO and S16. Open red circle corresponds to the area of hypocenter of the event.

identical events. Many of these sources are assumed to be cryoseismic origins from the comparison with satellite image around the LHB. The cryoseismic events are classified into several categories on the basis of their hypocentral location. That is, they contain ice-quakes associated with calving of glaciers, discharge of sea-ice, collision between sea-ice and icebergs. Detail and continuous measurements of infrasound in Antarctica are a new proxy for monitoring surface environment as well as climate change in high southern latitude.

\section{Acknowledgements}

We would like to express our sincere appreciation to many people who collaborated in the infrasound observations at SYO and other field stations in LHB, as well as members of the Japanese Antarctic Research Expeditions (JARE).

\section{References}

[1] Hedlin, M., Garces, M., Bass, H., Hayward, C., Herrin, G., Olson, J.V. and Wilson, 
C. (2002) Listening to the Secret Sounds of Earth's Atmosphere. Eos Archives, 83, 564-565. https://doi.org/10.1029/2002eo000383

[2] Iyemori, T., Nose, M., Han, D.S., Gao, Y., Hashizume, M., Choosakul, N., Shinagawa, H., Tanaka, Y., Utsugi, M., Saito, A., McCreadie, H., Odagi, Y. and Yang, F. (2005) Geomagnetic Pulsations Caused by the Sumatra Earthquake on December 26, 2004. Geophysical Research Letters, 32, L20807. https://doi.org/10.1029/2005gl024083

[3] Le Pichon, A., Herry, P., Mialle, P., Vergoz, J., Brachet, N., Garcés, M., Drob, D. and Ceranna, L. (2005) Infrasound Associated with 2004-2005 Large Sumatra Earthquakes and Tsunami. Geophysical Research Letters, 32, L19802. https://doi.org/10.1029/2005gl023893

[4] Wilson, C.R. and Olson, J.V. (2005) Frequency Domain Coherence between High Trace-Velocity Infrasonic Signals at I53US and Video Data from Pulsating Aurora. Inframatics, 9, 27-30.

[5] Matoza, R.S., Hedlin, M.A.H. and Garces, M.A. (2007) An Infrasound Array Study of Mount St. Helens. Journal of Volcanology and Geothermal Research, 160, 249262. https://doi.org/10.1016/j.jvolgeores.2006.10.006

[6] Arrowsmith, S.J., ReVelle, D.O., Edwards, W.N. and Brown, P. (2008) Global Detection of Infrasonic Signals from Three Large Bolides. Earth, Moon and Planets, 102, 357-363. https://doi.org/10.1007/s11038-007-9205-Z

[7] Le Pichon, A., Blanc, E. and Drob, D. (2005) Probing High-Altitude Winds Using Infrasound. Journal of Geophysical Research, 110, D20104.

https://doi.org/10.1029/2005jd006020

[8] Wilson, C.R. (1969) Auroral Infrasonic Waves. Journal of Geophysical Research, 74, 1812-1836. https://doi.org/10.1029/JA074i007p01812

[9] Yamamoto, M.-Y., Ishihara, Y. and Kanao, M. (2013) Infrasonic Waves in Antarctica: A New Proxy for Monitoring Polar Environment. International Journal of Geosciences, 4, 797-802. https://doi.org/10.4236/ijg.2013.44074

[10] Ishihara, Y., Kanao, M., Yamamoto, M.-Y., Toda, S., Matsushima, T. and Murayama, T. (2015) Infrasound Observations at Syowa Station, East Antarctica: Implications for Detecting the Surface Environmental Variations in the Polar Regions. Geoscience Frontiers, 6, 285-296. https://doi.org/10.1016/j.gsf.2013.12.012

[11] Murayama, T., Kanao, M., Yamamoto, M.-Y., Ishihara, Y., Matshushima, T. and Kakinami, Y. (2015) Infrasound Array Observations in the Lützow-Holm Bay Region, East Antarctica. Polar Science, 9, 35-50. https://doi.org/10.1016/j.polar.2014.07.005

[12] Cansi, Y. (1995) An Automatic Seismic Event Processing for Detection and Location: The P.M.C.C. Method. Geophysical Research Letters, 22, 1021-1024. https://doi.org/10.1029/95GL00468

[13] Cansi, Y. and Klinger, Y. (1997) An Automated Data Processing Method for MiniArrays, CSEM/EMSC European-Mediterranean Seismological Centre. Newsletter of the European-Mediterranean Seismological Center, 11, 1021-1024. 
Submit or recommend next manuscript to SCIRP and we will provide best service for you:

Accepting pre-submission inquiries through Email, Facebook, LinkedIn, Twitter, etc. A wide selection of journals (inclusive of 9 subjects, more than 200 journals)

Providing 24-hour high-quality service

User-friendly online submission system

Fair and swift peer-review system

Efficient typesetting and proofreading procedure

Display of the result of downloads and visits, as well as the number of cited articles Maximum dissemination of your research work

Submit your manuscript at: http://papersubmission.scirp.org/

Or contact ijg@scirp.org 